\title{
1828-29 OSMANLI-RUS HARBI'NDE \\ ERZURUM EYALETI'NDEN RUSYA'YA GÖÇÜRÜLEN ERMENILERIN GERi DÖNÜŞLERINI SAĞLAMA FAALIYETLERI
}

\author{
Activities To Grant The Return of Armenians \\ Who Were Forced To Migrate From The State of Erzurum to Russia DuringThe \\ 1828-29 Ottoman-Russian War.
}

\section{Dr. Besim ÖZCAN*}

\section{ÖZ}

Birçok önemli gelişmelerin yaşandığı 1828-29 Osmanlı-Rus Harbi, özellikle Rumeli ve Doğu Anadolu'da yaşayan Ermeni halkı için de telafisi mümkün olmayan neticeler doğurmuștur. Harb sırasında Rusya'nın yanında yer alan bu gayrimüslimler, harb sonunda Ruslar tarafindan zorla Rusya'ya göç ettirilip yeni yerlerine yerleştirilmişlerdir. Rusya bu suretle hem Türklerin Osmanlı ülkesine göçleri sebebiyle boş kalan arazileri kullanılır hale getirmeyi, hem de idaresi altında bulunacak bu Ermenileri Osmanlı hakkında beslediği emeller doğrultusunda kullanmayı hedeflemiştir. Ancak Osmanlı idaresinde sahip oldukları hak ve imtiyazları orada bulamayan bu insanlar geri dönüş için çeșitli çareler aramaya bașlamıșlardır. Erzurum örneğinin ele alındığı bu çalışmada, Erzurum ve çevresinden göçürülenlerin geriye dönüşlerini sağlama işi, Erzurum'da yaşayan dini liderlerce yürütülmüştür. Bunlar Osmanlı Hükümetine müracaatta bulunarak onların ülkelerine geri dönme isteklerini ifade edip kabulünü dilemişlerdir. Bu yolla sayıları tam belirlenemeyen birçok Osmanlı vatandaşı Ermeni, Erzurum'a, kendi evine dönme sevincini yaşamıștır. Bu durum Rusya ve Osmanlı idarelerinin halklarına sağladığı rahat ve huzurun değerlendirilmesi açısından da önemli bir örnek teşkil etmiştir.

Anahtar sözcükler: 1828-29 Osmanlı-Rus Harbi, Rusya, Osmanlı Devleti, Erzurum, Ermeniler, Göç.

\section{ABSTRACT}

1828-1929 Ottoman-Russian war, when severa important development stock place, had particularly caused irreparable consequences for Armenians living in Rumelia and Eastern Anatolia back then. These on-Muslims, who fought on Russia's side during the war, were forced to migrate Russia and settled there. By doing so, Russia was planning to make use of empty fields due to Turkish immigration to Ottoman State, and also to use Armenians in line with their ambitions. But Armenians, who did not have the same right and privileges in Russia as they had under Ottoman rule, started to look for the opportunity to return. They applied to the Ottoman Government and expressed their desire to return. There turn project for Armenians, who were living in grater Erzurum area before, was carried out by religious leaders living in Erzurum. In this way, undetermined number of Ottoman Armenians has experienced the joy of returning their home. These cassettes an important example for evaluating the comfort and peace of mind provided by Russia and Ottoman State's towards their citizens.

Key words: 1828-29 Ottoman-Russian War, Russia, Ottoman State, Erzurum, Armenians, Immigration.

\footnotetext{
* Atatürk Üniversitesi Edebiyat Fakültesi Tarih Bölümü Öğretim Üyesi bozcan@atauni.edu.tr
} 
XIX. yüzyıl Osmanlı Devleti'nin geleceği açısından önemli tarihi olaylara sahne olmuştur. Bu asra gelindiğinde artık çok güçlü hale gelmiş olan Rusya'nın artan baskıları ve yapılan savaşlarda elde ettiği başarılar Osmanlıyı zor durumda bırakmıştır. Balkanlar'da Avusturya'nın da bir tehdit unsuru olarak ortaya çıkması durumu daha da kötüleştirmiştir'. Başlangıçta bir kara devleti olarak tarih sahnesine çıkan Rusya, ülke sınırlarını genişletmek ve denizlere ulaşmak gayesiyle kuzeye ve güneye doğru sistemli bir şekilde yayılma politikasını benimsemiştir. Çar 1. Petro'nun (1696-1725) belirlediği ifade edilen bu hedeflerin ${ }^{2}$ gerçekleştirilmesine çalışılması Rusya'yı kuzeyde İsveç ${ }^{3}$, güneyde Osmanlı Devleti ile karşı karşıya getirmiş ve neticede taraflar arasında savaşların yapılmasına sebep olmuştur. Rusya'nın 1696'da Azak kalesini zapt etmesi ile Osmanlı ile başlattığı mücadele, 1711 Prut Savaşından sonra 1736-39, 1787-92, 1806-12, 1828-29 ve diğer harplerle sürüp gidecektir. ilk mücadele neticesinde 1699'da imzaladı̆̆ı Karlofça Antlaşması ile Karadeniz'e ayak basan Rusya, bundan sonra bütün XVIII. yüzyıl boyunca, Kafkaslar ve Balkanlar doğrultusunda olmak üzere Karadeniz'deki kıyılarını genişletmeye devam etmiş ve Balkanlarda Tuna'nın kollarından Prut nehrine kadar inmiştir ${ }^{4}$.

Bu harb, siyasi, askeri, ekonomik ve sosyal bakımlardan dikkate değer gelişmelere sebep olması yanında, iki devlet arasındaki münasebetlerde birçok ilklerin yaşanması neticesini doğurmak bakımından da oldukça önem arz etmektedir $^{5}$. Zira Rus orduları Rumeli cephesinde ilk defa Balkanları aşarak Edirne dâhil birçok yerleri zapt etmiş, Doğu Anadolu cephesinde ise başta Kars ve Erzurum olmak üzere en önemli müstahkem mevkileri ele geçirmiştir. Harp sonunda imzalanan Edirne Antlaşması (14 Eylül 1829) ile askeri ve politik üstünlük sağlayıp birçok yerler elde eden Rusya, Osmanlı Devleti'ni ağır bir harp tazminatı ödemeye de mecbur bırakmıştır. Bu suretle, Osmanlı Devleti'ni mâlî iflasa sürüklemeyi hedeflemiştir ${ }^{6}$. Yine ilk defa olarak Rusya işgali altında tuttuğu Rumeli ve Doğu

' Fahir Armaoğlu, 20. Yüzyıl Siyasi Tarihi (1914-1980), Ankara 1983, s. 43.

${ }^{2}$ Rus Çarı l. Petro'nun vasiyetnamesi olarak da ifade edilen bu hedefler hakkında bk. Ahmed Cevdet Paşa, Tarih-i Cevded-Tertib-i Cedid, ìstanbul 1303, l, s. 354-357.

${ }^{3}$ Rusya, İsveç'le yaptığı mücadelede başarılı olup 172ı'de imzaladığı antlaşma ile Baltık Denizi'ne çıkmayı başarmıştır. Akdes Nimet Kurat, Rusya Tarihi, Ankara 1993, s. 262.

${ }^{4}$ Karlofça Antlaşması'nın muhtevası için bk. Nihat Erim, Devletlerarası Hukuku ve Siyasi Tarih Metinleri, Ankara 1953, 1, s. 23-35.

${ }^{5}$ Osmanlı Devleti'nin ağır yenilgisi ile sona eren bu harbin teferruatı için bk. Ahmet Muhtar Paşa, 1244-1245 Türkiye-Rusya Seferi ve Edirne Antlaşması, Ankara 1928; Türk Silahlı Kuvvetleri Tarihi (1793-1908), Ankara 1978, 111/5, s. 433-450.

${ }^{6}$ Edirne Antlaşması ile Osmanlı Devleti Rusya'ya harp tazminatı olarak 10 milyon ve Rus tüccarlarının zararlarına karşıı 1.5 milyon olmak üzere toplam 11.5 milyon Macar altını ödemeyi kabul etmiştir. Bu antlaşmanın maddeleri ve değerlendirilmesi hakkında bk. Şerafettin Turan, 
Anadolu'da yaşamakta olan ve savaş esnasında kendi lehlerinde hareket ettikleri görülen çok sayıdaki Osmanlı reâyâsını yerlerinden kaldırıp kendi ülkesine göçürme projesini uygulamıştır. Doğu Anadolu bölgesinde uyguladığı göçü, Rumeli örneğinden çok daha geniş kapsamlı ve organize bir şekilde icra etmeye çalışmıştır. Her iki konu hakkında çok değerli iki çalışma yapılarak göçürme hadisesi bütün yönleri ile ortaya konulmuştur ${ }^{7}$. Bu makalede özellikle Erzurum'un Rus işgaline düşmesini müteakip, Doğu Anadolu'da ikamet etmekte olan Ermenilerin nasıl ve hangi şartlar çerçevesinde göçe zorlandıkları konusu kısaca verilip, bilhassa zorlama ve birçok vaatler neticesinde Erzurum'dan göçürülen ve gittikleri yerlerde Erzurum'da sahip oldukları huzur ve imkânları bulamayan Ermenilerin geri dönüşlerini sağlamak gayesiyle Erzurum'daki Ermeni, Katolik ve Rum liderlerinin teşebbüsleri hakkında bilgi verilecektir.

Rus kuvvetleri 1828'de savaşın başlamasını müteakip hızla hareket ederek, içerdekilerin yardımı ile Kars'ı, ardından da Ahıska'yı ele geçirmişlerdi. Rusların bu muvaffakiyeti, Müslüman ahalinin gayretini kırmıştır. Ayrıca Rusya'ya tâbi olan Ermenilerin, Müslümanlara ihanet edip eziyete kalkışmaları, düşmana karşı genel direnişi zayıflatmakta ve kırmakta, kaleleri içten feth ettirmekteydi. Ciddi bir mukavemet göstermeden düşmana kapılarını açan ve içinde en az 20-25 bin kadar Ermeni nüfusu olduğu tahmin edilen Erzurum'da da durum pek farklı olmamış ve şehir kolaylıkla düşmanın eline geçmiştir ${ }^{8}$. Üç ay kadar sürecek olan bu işgal, Erzurum'a pahalıya mal olmuş ve büyük ölçüde zarar vermiştir. Çünkü Müslüman halkın bir kısmı başka yerlere göç ettiği gibi, Ruslar çekilirken çoğu sanat erbabı olan Ermenileri de birlikte götürdüler. Şehri yağmalayan ve pek çok nadide sanat eserlerini de beraberlerinde götüren Ruslar, İçkale'yi tahkim etmek üzere taş ihtiyacını gidermek için birtakım cami, türbe ve binaları da yaktılar 9 .

Doğu Anadolu'nun Ruslar tarafından işgali sırasında bölgede yaşayan ve sayıları hiçbir devirde müslüman nüfusun üçte birini aşamayan Ermeni ve Rumların bir kısmının Türklere ihanet ederek düşmana yardımda bulundukları anlaşılmaktadır. Rusya, arazide ilerlemelerini kolaylaştırmak ve Türk tarafının kıta harekâtı ve mevki durumu hakkında istihbarat için kendisine karşı meyli olan Ermenilerden istifade etmiştir. Bölgede yaşayan gayrimüslimler işgal sırasında da

"Edirne Antlaşması, Ankara Üniversitesi Dil ve Tarih Coğrafya Fakültesi Dergisi, IX, sayı: 1-2, Ankara Mart-Haziran 1951, s. 111-151.

${ }^{7}$ Ruslar tarafından Rumeli'den göçürülen reâyâ hakkında geniş bilgi için bk. Ufuk Gülsoy, 1828 1829 Osmanlı-Rus Savaşı'nda Rumeli'den Rusya'ya Göçürülen Reâyâ, ìstanbul 1993. Doğu Anadolu'dan göçürülen Ermeniler hakkında ise bk. Kemal Beydilli, 1828-1829 Osmanlı-Rus Savaşı'nda Doğu Anadolu'dan Göçürülen Ermeniler (Türk Tarih Kurumu, Belgeler, Türk Tarih Belgeleri Dergisi, c. XIII, sayı: 17'den ayrı basım), Ankara 1988.

${ }^{8}$ Beydilli, 1828-1829 Osmanlı-Rus Savaşı'nda Doğu Anadolu'dan Göçürülen Ermeniler, s. 384.

${ }^{9}$ Cevdet Küçük, "Erzurum", Diyanet islâm Ansiklopedisi (DiA), 11, s. 324. 
$198{ }^{*}{ }^{\text {TAED }} 46$

Müslüman halka karşı kötü muamele yapmaktan çekinmemişlerdir. Nitekim bu husus devrin vak'anüvisi Ahmet Lütfi Efendi tarafından, “.. Ermeni ve Rum teb'asının ehl-i İslâm'a etmedikleri ihânet ve cevr ü ezâ kalmamış olduğunu bilbeyân asker ve mühimmât yetiștirilmesini ve işlerin imdâd-ı mánevî̀-i ilâhiye kalmış olduğunu Erzurum valisi Galib Paşa Babıâlîye bildirmiştir ${ }^{\text {"Io }}$ ifadesiyle açıkça izah edilmektedir.

Rusya savaş öncesinde Türk sınırları içinde yaşayan ve toplum üzerinde büyük etkileri bulunan Ermeni din adamlarını elde ederek savaş sırasında onların kendi lehlerinde hareket etmelerini sağlamıştır. Savaşın bitmesini müteakip Doğu Anadolu'da uygulamaya koyduğu göçürme harekâtında da bu din adamlarından istifade etmiştir. Öte yandan Rus işgal komutanı General Pankratyev işgal sırasında planlı bir şekilde hareket ederek yine Ermeni tâbiiyetini kabul etmiş olan din adamlarından yararlanarak Ermeni halka baskı uygulamaya başlamıştır. Nitekim Rusya ile olan işbirliği ve devlete ihanetini önceleri gizlemeyi uygun gören Karabaş, Ermeni halkını "alenen cebr ü tazyik" ettiği gibi dellal nida ettirip; "Rusya'ya gitmek isteyenler Karabaşın defterine ve kalanlar dahi mahallât imamlarının defterine yazılsınlar ve mahalle imamı defterine yazılanların emvâli gârât (malları yağma) ve hanesi ihrak (evleri yakılacak) olunacaktır" tehdidiyle göçe zorlamıştır. Tehdide rağmen gitmek istemeyenler şiddetli bir şekilde dövülerek zulm ve eziyete tabi tutulmuşlardır. Bu suretle Ermeni rahipleri vasıtasıyla Karabaş adına, Erzurum içinde, ova köylerinde, Pasin, Mecingerd, Hınıs, Tekman ve Tırhan kazalarında yürütülen yoğun propaganda ve her türlü kışkırtma ve korku ile reâyâ deftere kaydedilmekteydi".

Rus işgalinin devam ettiği bölgelerde bu tür baskı ve zoraki göçürmenin yaşanabileceğini önceden tahmin etmiş olan Osmanlı Hükümeti, bunun önüne geçilebilmek için bazı tedbirlere de başvurmuştu. Ancak Rusya tarafına gitmek isteyenlere, Edirne Antlaşması'nın nakl-i reâyâya dair 13. firkası gereğince bir şey yapmak mümkün değildi. Bu gelişmeler çerçevesinde Ruslar kayıtlara göre Doğu Anadolu bölgesinden 100.000'e yakın insanı kendi topraklarına göçürmeyi başarmıştır. Bu suretle Rusya, kendi ülkesinde boş bulunan yerlerde bir işgücü oluşturmayı ve bu gayrimüslim toplulukları Osmanlı toprakları üzerindeki emelleri doğrultusunda kullanma hedefini de gerçekleştirme fırsatını elde etmiştir. Erzurum Eyâleti'nden göçürülen Ermenilerin sayısı göçürülenlerin hane ve emlâklerinin kaydedildiği defterlerde açıçca kaydedilmiştir. Buna göre, şehir merkezinden 2.372 hane, ova köylerinden 1.139 hane, Pasin kazasından 561 hane, Hınıs kazasından 468 hane, Tercan kazasından 33 hane, Bayburt kazasından 40

\footnotetext{
${ }^{10}$ Ahmed Lütfi Efendi, Vak'anüvis Ahmed Lütfi Efendi Tarihi (yeni yazıya aktaran: Yücel Demirel, Tamer Erdoğan), ístanbul 1999, c. 2-3, s. 371.

" Beydilli, 1828-1829 Osmanlı-Rus Savaşı'nda Doğu Anadolu'dan Göçürülen Ermeniler, s. 388.
} 
hane ve Tortum kazasından da 117 hane olmak üzere toplam 4.730 hanedir. Her hane ortalama beş nüfus olarak kabul edildiğinde göçürülen toplam Ermeni nüfus 23.650 kişi civarındadır ${ }^{12}$.

Erzurum ve çevresinden göçürülüp Erivan, Ahılkelek ve Ahıska bölgelerine yerleştirilen bu Ermeniler ${ }^{13}$ yeni hayat sahalarında istedikleri rahata kavuşamadılar. Pologenia adı verilen yasa dolayısılla pek çok zarara uğradılar. Vergi yanında askerlik ile de yükümlü olmaları, bunları iyice bezdirmiş, çoğu yoksulluktan açlık ve perişanlık içinde kalmışlardır ${ }^{14}$. Buna mukabil Osmanlı Hükümeti, tabiiyeti altında yaşayan azınlıkların her türlü haklarını kullanmalarına son derece ehemmiyet gösterdiği gibi, 3 Kasım 1839 tarihinde ilân ettiği Tanzimat Fermanı ile azınlıklara verilmiş olan hakları belgeye dayandırmış, bütün vatandaşların can, mal ve namus güvenliğinin devlet tarafından sağlanacağını beyan etmiştir ${ }^{15}$. Rusya tarafından vaad edilen hayat şartlarının çok altında imkân tanınan bu insanlar, Türkiye'de yaşamakta olan azınlıkların daha iyi imkânlara kavuştuklarını da öğrendiklerinden Rusya'ya gittiklerine pişman olmuşlar ve tehlikeli olmasına rağmen gizli yollarla geriye, eski yerlerine dönmeye çalışmışlardır. Esasında bu dönüş hareketi, Erzurum valisi Ali Şefik Paşa'nın 30 Haziran 1830 tarihli bir kaimesinde ifade olunduğu üzere, daha göç yolunda iken başlamış, pişman olan bazı Ermeniler, Kars'a varmadan firsat buldukları anda ailelerini dahi terk ederek geriye kaçmışlar, Ruslara yakalanmamak için çeşitli yerlerde saklanmışlardı. Nitekim aynı yıl içinde 100 hanenin bir fırsatını bulup Erzurum'a döndüğü ve diğerlerinin de fırsat bulmaları halinde geriye dönmeye hazır oldukları ifade edilmiştir $^{16}$. Erzurum valisi bir başka yazısında, Rusların göçürmüş oldukları Ermenilerin geriye dönüşlerini engellemek için her türlü tedbiri almış olduğunu, bu cümleden olarak Ahıska'ya yerleştirmiş oldukları Erzurum Ermenilerinin kaçmaya taraftar olduklarını anladığından burayı sıkı bir kontrole tabi tuttuğunu belirtmiş$\operatorname{tir}^{17}$.

Yaşanan bu olayların ardından özellikle zikredilmesi gereken hususlardan birisi şüphesiz Osmanlı Hükümeti ve devlet adamlarının bu geriye dönen Ermenilere gösterdiği yakınlıktır. Nitekim onların yerlerini terk etmelerini müteakip mal varlıklarını kaydedip emniyet altına alan mahalli yetkililer, geriye dönenlere

\footnotetext{
${ }^{12}$ Muammer Demirel, “1828-1829 Osmanlı-Rus Savaşı'nda Rusya'ya Göçürülen Ermenilerin Geri Dönüşü",XIV. Türk Tarih Kongresi, Kongreye Sunulan Bildiriler, (Ankara, 9-13 Eylül 2002), Ankara, 2006, ll. cilt l. kısım, s. 268.

${ }^{13}$ Kâmuran Gürün, Ermeni Dosyası, Ankara 1993, s.57.

${ }^{14}$ Enver Konukçu, Selçuklulardan Cumhuriyete Erzurum, Ankara 1992, s.704.

${ }^{15}$ Tanzimat Fermanı ile gayrimüslimlere tanınan hak imtiyazlar için bk. Ali Akyıldız, "Tanzimat", $D i A$, ìstanbul 2011, 40, s. 1-10.

${ }^{16}$ BOA, Hatt-ı Hümayun, Nr. 43212-A.

${ }^{17}$ BOA, Hatt-ı Hümayun, Nr. 43294-A.
} 
mal ve mülklerini teslim ederek onların sefalet ve darlı̆ga düşmelerini engellemişlerdir. Hükümet, üretimin devamını sağlamak için boş kalan araziyi tesbit etmek ve ayrıca emlâk ve arazilerini satamadan gidenlere bedellerini ödemek üzere düzenli bir şekilde kayıt tutturmuştu.

Rusya'da yaşama şartlarının kötü olması dolayısıyla gidenlerin geriye dönüşlerini sağlamak ve Osmanlı idaresi altında sahip oldukları asayiş ve rahatlı̆̆ın teşekkürünü ifa etmek maksadıyla ülkede yaşayan gayrimüslimler tarafindan Osmanlı Hükümetine bazı müracaatlar olmuştur. Bunlar içinde zikre değer mahiyette olan arizalar 1853 yılı içinde Erzurum Eyâleti'nde yaşayan Ermeniler ile Rumlar tarafindan kaleme alınmıştır.

Erzurum'da Rum ve Katoliklerin Ermenilere göre az olması sebebiyle bu iki cemaatin işlerine Ermeni murahhası nezaret etmekte olduğundan Katolikler de Ermeni murahhası riyasetinde isteklerini ihtiva eden yazılarını yazmış ve hususiyle aralarında herhangi bir mesele olmadığını ve huzur içinde yaşadıklarını ifade etmişlerdir.

“Rabbimiz Te'âlâ ve takaddes hazretleri șevketlü, mahabbetlü, kudretlü, azametlü veliyyi-nimet-i bî minnetimiz Padişahımız efendimiz hazretlerine bitmez ve tükenmez ömürler ihsan buyursun. Âmin" dua metni ile başlayan Katoliklerin 12 Temmuz 1853 tarihli arizalarında İslâm padişahı olan Efendilerinin huzur dolu memleketinde yaşamaktan son derece mutlu ve memnun olduklarını arz etmişlerdir. Yazının devamında, bir süre önce vatanı terkedip başka yerlere giden halktan bazılarının oradaki yaşantıyı beğenmeyerek tekrar huzur dolu ülkeye döndükleri, orada kalanların ise çok kötü bir hayat sürdürdükleri belirtilmiş, Erzurum'da ikamet eden bu Katolik kullarının huzur ve asayiş içinde yaşadıkları ve Padişah Efendilerinin teveccühlerine âmâde oldukları ifadelerine yer verilmiștir. Yazının altında Katolik milleti Murahhası ile Katolik milleti Erzurum muhbirinin imzaları bulunmaktadır ${ }^{18}$. Toplam 85 mührün yer aldığı tezkerede bazı mühürler Osmanlıca, büyük bir kısmı ise Ermenicedir.

Mâbeyn Başkâtipliğine sunulan tezkere ekinde Katolik milleti murahhası tarafından yazılmış bir teşekkürnâme de mevcuttur. Yazıda, Katolik topluluğu olarak yüce padişahlarının varlı̆̆ından duyulan memnunluk ve hoşnutluktan ötürü geçmişlerinde de olduğu gibi büyük bir nimet telakki ettiklerinden takdimine cesaret ettikleri teşekkürnâmenin Padişaha arz edilmesi hususunda niyaz ve istirhamda bulunulmuştur ${ }^{19}$.

${ }^{18} B O A$, irâde-Meclis-i Vâlâ (iR-MV), Nr. 11099, Leffi (L) : 2.

${ }^{19} B O A$, iR $-M V$, Nr. 11099 , L. 3. 
Erzurum gayrimüslimlerinin, Erzurum ve havalisinde mütemekkin Hıristiyan reâyâ kulları ifadesiyle kaleme aldıkları bir başka ariza üzerinde ${ }^{20}$, Erzurum Ermeni muhbirinin yanısıra birçok mahalle muhbiri mührüyle beraber toplam 380 mühür bulunmaktadır. Yazı "Cenâb-ı Hazret-i Hakk ve Feyyâz-i mutlak hazretleri Padişahımız efendimiz hazretlerine bitmez ve tükenmez ömürler ihsan buyurup her bir umur meyâmin-i şâhânelerinde tevfikât-ı ilâhiyyesin yaver ve rehnümûn buyursun. Âmin! Sümme âmîn!.” dua metni ile başlamaktadır. Devamında, Erzurum'da yaşayan Hıristiyan toplumunun huzurunun, teşekküründen aciz oldukları derecede yerinde olduğu, çoluk-çocuk ve mal ile mülklerinin devletin muhafazası altında olduğu vurgulanmıştır. Bundan önce vukubulan Rusya istilâsı sırasında kendilerinin Rusya tarafına meyletmeyerek Padişah hazretlerinin emrinde bulunduklarını ve bundan böyle de bulunmaya devam edeceklerini ifade etmişlerdir. Bu istilâ sırasında bazı kimseler yalnız veya aileleri ile beraber Rusya tarafına gitmişlerse de burada sahip oldukları huzur ve asayişi orada bulamayıp firar ile bu tarafa kemâl-i hâhişle gelmişlerdir. Bundan sonra ecdatları gibi yine Padişah ve devlete sadıkane bağlı yaşayacakları sözünü veren gayrimüslimler, bu hususun Babıâli'ye bildirilmesi ricasında bulunmuşlardır.

Erzurum Valiliğine sunulup Babıâli'ye gönderilmesi istenen bu tezkereler, Erzurum valisi Mustafa Paşa'nın 11 Temmuz 1853 tarihli arzı ile Meclis-i Vâlâ'ya gönderilmiştir. Vali arzında ${ }^{21}$, “... alel-husus reâya ve hıristiyan takımı hiçbir vakitte görmedikleri lütuf ve şefkat-ı seniyye ve hüsn-i muhafazat ve himaye-i aleniye teşekküren" ifadesiyle Erzurum Eyâleti içinde oturan Ermeni ve Katolik toplumlarının kendilerine sağlanan asayiş ve huzur dolayısıyla müteşekkir olduklarını belirtmiştir. Önceleri Revan'a gitmiş olup bu huzur dolu hayatı duyan Ermenilerin "kemâl-i şevk ve hahiş ile" ile bu tarafa gelmeye devam ettikleri ve onlarla beraber bu güzel durumdan dolayı bağlılıklarının bir nişanesi olarak kendi kiliselerinde Padişaha dua etmekte oldukları hususunun da yer aldığı bu yazıda, Rum ve Ermeni milletleriyle, Katolik takımı tarafindan mevcut idareden dolayı "kemâl-i teşekkür ve memnuniyeti ve ibrâz-ı sıdk ve ubûdiyeti" ifade etmek üzere, onların bu güzel günlere kavuşmalarını sağlayan Padişahlarına sunulmak üzere yazdıkları arizaların ekte sunulduğu açıklanmıştır.

Vali Mustafa Paşa'nın yazısıyla gelen Erzurum gayrimüslimlerinin arizalarının Padişaha arzedilmek üzere Mâbeyn Başkâtipliğine sunulan tezkere aynen şöyledir ${ }^{22}$;

${ }^{20} B O A$, iR $-M V$, Nr. 11099, L. 4.

${ }^{21} B O A, I R-M V, N r .11099$. Mustafa Paşa'nın bu arzından Erzurum'da yaşayan gayrimüslimlerden Ermenilerin (çoğunluğu Gregoryen ve bir miktarı da Katolik) nüfusça kalabalık oldukları ve az sayıda da Rumların yaşadığı anlaşılmaktadır.

${ }^{22} B O A$, IR-MV, Nr. 11099, L. 1, Fi 6 Zilkade sene 1269 (11 Ağustos 1853). 


\section{“Atûfetlü Efendim Hazretleri,}

Erzurum Eyâleti dâhilinde mutavattın Rum, Ermeni ve Katolik milletlerinin sâye-i muvaffakıyet-vâye-i hazret-i cihandârîde mazhar ve nâil oldukları asayiş ve huzuru mukaddema Revan tarafina gitmiş olan reâyâ işitüp kemâl-i şevk ve hâhişle refte refte gelmekte ve da'vât-ı fuzuli-i ömr-i şevket-i hazret-i padişâhi yâd ve tezkâr kılınmakta olduğuna dair Erzurum valisi devletlü Paşa hazretleri tarafindan gelen tahrirat ve evrak üzerine Meclis-i Vâlâ'dan kaleme alınan mazbata evrakıyla meşmûl-i nazar-ı âli buyurulmak için arz ve takdim kılındı. Bunların bu suretle avdetleri usul-ı adliye âsâr-ı celilesinden olduğu cihetle bundan böyle dahi himâye-i reâyâya himmet ve itinâ olunması vesâyasıyla mahzuziyeti hâvi vali-i müşârün-ileyhe cevab-nâme yazılması tezekkür olunmuş ise de olbabda her ne vechile emr ü fermân-ı cenâb-ı mülükâne müteallık buyurulur ise ana göre hareket olunacağı beyaniyle tezkere-i senâveri terkim kılındı efendim".

13 Ağustos 1853'te çıkan irade ile tezkerede konu edilen Ermenilerin dönüşlerine izin verilmesi ve "bundan böyle dahi himâye-i reâyâya himmet ve itinâ olunması vesâyasıyla mahzuziyeti hâvi vali-i müşâüun-ileyhe cevab-nâme yazılma$s \boldsymbol{s}$ " hususunun Padişah tarafından uygun bulunduğu açıklanmıştır.

Padişahın izni çerçevesinde yeniden eski yerlerine dönmek isteyen Ermeni, Katolik ve az sayıdaki Rum, kendi cemaat defterine kaydedilmek suretiyle Erzurum'a yerleştirilmiştir. Dönüş yapıp Erzurum'a yerleştirilen Ermenilerden 570 kişi Ermeni defterine kaydedilirken bunlar arasında bulunan 10 Rum da Rum Patrikhanesi defterine yazılmıștır ${ }^{23}$. Yine dönüșlerine müsaade edilen 228 hane 622 nüfuslu Katolik Ermeniler de kendi defterlerine kaydı yapıldıktan sonra şehir merkezine yerleştirilmişlerdir ${ }^{24}$.

Bu şekilde devam eden yurda dönüşlerin Kırım Savaşı sırasında Rusların sıkı kontrollerinin hafiflemiş olması sebebiyle daha da arttığı ve bu hareketin 93 Harbi diye de bilinen 1877-78 Osmanl-Rus savaşına kadar devam ettiği anlaşılmaktadır. Osmanlı ülkesine dönüşün uzun bir süre devam ettiği dikkate alındığında dönenlerin miktarı hakkında kesin bir bilgi ve rakam vermek mümkün görünmemektedir.

Gayrimüslimlerin Osmanlı idaresi altında yaşamaktan dolayı duydukları memnuniyet, 1829 'da zorla Rusya'ya göçürülenler içinde yer alıp sonradan ülkeye dönmüş ve Erzurum mebusu seçilmiş bir Ermeni'nin 1877'de Meclis-i Mebusan'da yaptığı konuşmada apaçık dile getirilmektedir ${ }^{25}$ :

${ }^{23}$ BOA, Hariciye- Mektubi Kalemi (HR..MKT), Nr. 82/93.

${ }^{24} B O A, H R . . M K T, \mathrm{Nr} .89 / 95$.

${ }^{25}$ Konukçu, Selçuklulardan Cumhuriyete Erzurum, s.704. 
“Ermenilerin beşyüz seneyi aşan Osmanlı Devleti vatandaşlığında gördükleri güven ve düzen ve himayeyi burada anlatmaktan âcizim. Ben dahi Erzurum mebusuyum. Kırksekiz sene önce (1829) Rusya'nın kandırması ile Erzurum'dan göç eden 100.000 nüfusla birlikte idik. Ancak Rusya'nın gayesini anlayarak Osmanlı topraklarına döndük". Ermeni mebusu, bu kısa, ama oldukça geniş bir mana taşıyan açıklaması ile sadece çok mühim bir gerçeğe işaret etmemiş, aynı zamanda kendi ailesi ve diğer Ermenilerin de pişmanlıklarını yıllar sonra bir kere daha dile getirmiştir.

Ermenilerin, Osmanlı idaresinde rahat ve huzur içinde yaşadıklarını ispat eden bir başka konuşma da yine aynı mecliste 13 Aralık 1878 tarihinde olmuştur. 1877-78 Savaşı sonrasında savaş tazminatı olarak Elviye-i Selâse denilen üç sancağın (Kars, Ardahan, Batum) Rusya'ya bırakılacağı yönünde gazetelerde çıkan haberlerle alakalı olarak mecliste Ermeni mebuslar adına Halep mebusu Manok Efendi bir konuşma yapmıştır. Manok Efendi oldukça önemli hususların yer aldı-

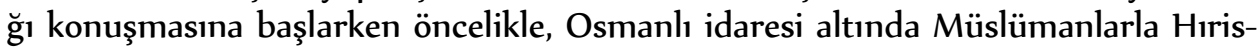
tiyanların birlik ve beraberlik içinde yaşadıklarını, mevcut sıkıntıları uzlaşma ile aralarında çözebileceklerini ifade ederek Ermenistan'da hudud düzenlemesinin nereden çıktığını sormuştur. Mebus konuşmasının devamında o güne kadar düşmanlara karşı birlikte verilen mücadelelere işaret ederek " ... böyle bir muti" ve şâyân-ı merhamet olan bir halkın ve daima devletin zîr-ı cenâhında yaşamak arzu-yi müftehiresinde bulunan edib tebeayı Rusya gibi bir despot devletin idaresi tahtında bulunmaklı̆g mecbur etmemeliyiz" ifadesiyle bu yerlerin ve orada yaşayan halkın despot olarak nitelendirdiği Rusya idaresine bırakılmasına karşı çıkmıştır. Meselenin çözümü konusunda tavsiye ettiği fikirleri ise şöyledir; “. Ermeni olarak bu mecliste bulunan arkadaşlarımla beraber Ermenistan namına hey'et-i âlinize arz ve beyan ederiz ki şayed Rusya devletine bir tazminat vermek lâzım geldiği taktirde öyle gazetelerin zu'mi üzerine Ermenistan'dan bir şey verilmeyip ihvanımızdan ayrılmamak için bunun akçaya tahvilini hâkipâ-yi hazret-i padişâhîden istirham edelim ve çare olmadığı halde işbu mikdar feryadımız millet namına olarak düvel-i mütehabbenin pîş-i nazarına havale olunması ve çaresiz kalıp da behemehâl Rusya'ya arazi verileceği surette Ermenistan'dan verilmeyip devlete her zaman gâile çıkarmağa sebep olan taraflardan aranılmasını niyaz ve istirham ederiz ${ }^{\prime 26}$. Bu ifadelerden anlaşılacağı üzere Mebus, tazminatın paraya çevrilmesi, bu mümkün olmayıp illa arazi verilmesi durumunda ise adı geçen yerlerin değil, devlete problem teşkil eden tarafların verilmesi teklifinde bulunmuştur.

\footnotetext{
${ }^{26}$ Ermeni mebusunun bu konuşmasının tam metni için bk. Meclis-i Mebûsân Zabit Ceridesi 1293-1877, (hazırlayan Hakkı Tarık Us), ístanbul 1954, s. 172-173.
} 
Erzurum'da ikamet etmekte olup 1828-29 Harbi sonrasında Rus kuvvetlerince zorla Rusya'ya götürülen Ermeni vatandaşların, Rusların kendilerine sağladığı yaşam şartlarını beğenmeyip evlerine dönmek için ortaya koydukları mücadele ve Ermeni mebuslarının beyanatları, iki ülke idarelerinin mukayesesi bakımından önem arz etmektedir. Ayrıca bu gayrimüslim topluluğunun Osmanlı idaresi altında kalmaya devam etmek istemeleri, burada huzur ve rahat içinde yaşamakta olduklarının da önemli bir delili olarak değerlendirilmelidir.

\section{KAYNAKÇA}

Ahmed Cevdet Paşa, Tarih-i Cevded-Tertib-i Cedid, l, ístanbul 1303.

Ahmed Lütfi Efendi, Vak'anüvis Ahmed Lütfi Efendi Tarihi (yeni yazıya aktaran: Yücel Demirel, Tamer Erdoğan), c. 2-3, İstanbul 1999.

Ahmet Muhtar Paşa; 1244-1245 Türkiye-Rusya Seferi ve Edirne Antlaşması, Ankara 1928.

AKYILDIZ, Ali; “Tanzimat”, Diyanet íslâm Ansiklopedisi, 40, ìstanbul 2011.

ARMAOĞLU, Fahir; 20. Yüzyıl Siyasi Tarihi (1914-1980), Ankara 1983.

BEYDiLli, Kemal; 1828-1829 Osmanlı-Rus Savaşı'nda Doğu Anadolu'dan Göçürülen Ermeniler

(Türk Tarih Kurumu, Belgeler, Türk Tarih Belgeleri Dergisi, c. XIII, sayı: 17'den ayrı basım),

Ankara 1988.

BOA, Hariciye- Mektubi Kalemi, Nr. 82/93.

BOA, Hariciye- Mektubi Kalemi, Nr. 89/95.

BOA, Hatt-1 Hümayun, Nr. 43212-A.

BOA, Hatt-1 Hümayun, Nr. 43294-A.

BOA, İrâde-Meclis-i Vâlâ, Nr. 11099; Leffi; 1,2, 3, 4.

DEMiREL, Muammer; “1828-1829 Osmanlı-Rus Savaşı'nda Rusya'ya Göçürülen Ermenilerin Geri

Dönüşü", XIV. Türk Tarih Kongresi, Kongreye Sunulan Bildiriler, (Ankara, 9-13 Eylül 2002),

Il. cilt l. kısım, Ankara, 2006.

ERiM, Nihat; Devletlerarası Hukuku ve Siyasi Tarih Metinleri l, Ankara 1953.

GüLSOY, Ufuk; 1828-1829 Osmanlı-Rus Savaşı'nda Rumeli'den Rusya'ya Göçürülen Reâyâ, ìstanbul 1993.

GÜRÜN, Kâmuran; Ermeni Dosyası, Ankara 1993.

KONUKÇU, Enver; Selçuklulardan Cumhuriyete Erzurum, Ankara 1992.

KURAT, Akdes Nimet, Rusya Tarihi, Ankara 1993.

KüÇÜK, Cevdet; "Erzurum", Diyanet İslâm Ansiklopedisi, 11,ístanbul 1995

Meclis-i Mebûsân Zabit Ceridesi 1293-1877, (hazırlayan Hakkı Tarık Us), ìstanbul 1954.

TURAN, Şerafettin ; "Edirne Antlaşması", Ankara Üniversitesi Dil ve Tarih Coğrafya Fakültesi

Dergisi, IX, sayı: 1-2, Ankara Mart-Haziran 1951.

Türk Silahlı Kuvvetleri Tarihi (1793-1908), 111/5, Ankara 1978. 